\title{
Correction to: Distribution of linear alkylbenzenes as a domestic sewage molecular marker in surface sediments of International Anzali Wetland in the southwest of the Caspian Sea, Iran
}

\author{
Alireza Riyahi Bakhtiari ${ }^{1}$ - Islam Javedankherad ${ }^{1}$ - Jahangard Mohammadi $^{2} \cdot$ Ruhollah Taghizadeh-Mehrjardi $^{3}$ \\ Published online: 30 January 2021 \\ (C) Springer-Verlag GmbH Germany, part of Springer Nature 2021
}

Correction to: Environmental Science and Pollution Research (2018) 25:20920-20929 https://doi.org/10.1007/s11356-018-1942-1

The correct name of the 4th Author is presented in this paper.

Publisher's note Springer Nature remains neutral with regard to jurisdictional claims in published maps and institutional affiliations.

The online version of the original article can be found at https://doi.org/ 10.1007/s11356-018-1942-1

Alireza Riyahi Bakhtiari

triahi@modares.ac.ir

1 Department of Environmental Science, Faculty of Natural Resources and Marine Sciences, Tarbiat Modares University,

P.O. Box 64414-356, Noor, Mazandaran, Iran

2 Department of Soil Science, College of Agriculture, Shahrekord University, P.O. Box 88186-34141, Shahrekord, Iran

3 Faculty of Agriculture and Natural Resources, University of Ardakan, P.O. Box 89516-56767, Yazd, Iran 